\title{
The Impact of Anxiety on Self - Concept and Adjustment of Adolescents with Learning Disabilities in Mumbai
}

\author{
Aastha Chaturvedi $i^{l}$ \\ ${ }^{1}$ Post Graduate Student, Department of Psychology, Maniben Nanavati Women's College, Mumbai. \\ E-mail - aasthachaturvedi92@gmail.com
}

\section{ABSTRACT}

The purpose of the current study was to investigate the relationship between anxiety, self - concept and adjustment among adolescent with learning disabilities (LD) in Mumbai. The study consisted of 59 male and 51 female adolescent students $(N=110)$ between ages fourteen to eighteen years who had been diagnosed with learning disability. The scales employed in the study were the Revised Children's Anxiety and Depression Scale - Child Version, which measured the anxiety of the participating adolescents, the Self - Concept Questionnaire, which measured the self-concept of the participating adolescents and the Adjustment Inventory for School Students, which measured the adjustment of the participating adolescents. The findings revealed that, anxiety and self - concept was negatively correlated. It also revealed that anxiety and adjustment were positively correlated. Regression analysis revealed that anxiety is predictive of self - concept. It also revealed that anxiety is predictive of adjustment.

Key words: adjustment, anxiety, learning disabilities and self-concept

\section{INTRODUCTION}

School learning is affected by many factors. The personal characteristics of the child, familial attributes and factors related to the school and class altogether affect the child's ability and potential to benefit from teaching. These factors influence the child's learning experiences and in the process affect the child's self-image as a learner, among many other attributes. These experiences, the child's beliefs, and his/her knowledge and skills, together with the characteristics of the environment, form a complex interactional system. Learning disabilities are not the only cause for difficulties in learning. It is often hard to distinguish a learning disability from a learning difficulty caused by something else, or to draw distinct boundaries for when a child has a learning disability and what the cognitive deficit is that predisposes them to the disability. According to this thinking, developmental difficulties and learning disabilities appear as a slower development in some specific skill area [1].

Learning disabilities are known as 'Learning Disorders', they are characterized by significantly sub - average intellectual functioning (an IQ of approximately 
70 or below) with onset before 18 years and concurrent deficits or impairments in adaptive functioning [2]. Learning disabilities is a general term that refers to a heterogeneous group of disorders manifested by significant difficulties in the acquisition and use of listening, speaking, reading, writing, reasoning or mathematical skills. These disorders are intrinsic to the individual, presumed to be due to the central nervous system dysfunction and may occur across the life span. Problems in self-regulatory behavior, social perception and social interaction may exist with learning disabilities but do not, by themselves, constitute a learning disability [3].

Reading, writing, and math aren't the only skills impacted by learning disorders. Other types of learning disabilities involve difficulties with motor skills, understanding spoken language, distinguishing between sounds and interpreting visual information.

1. Dyspraxia (Sensory Integration Disorder) - Difficulty with fine motor skills

2. Dysphasia/ Aphasia - Difficulty with language

3. Auditory Processing Disorder - Difficulty hearing differences between sounds

4. Visual Processing Disorder - Difficulty interpreting visual information

Difficulty in school doesn't always stem from a learning disability. Anxiety, depression, stressful events, emotional trauma, and other conditions affecting concentration make learning more of a challenge. In addition, ADHD and autism sometimes co-occur or are confused with learning disabilities. According to the American Psychiatric Association, as a child goes through adolescence, he or she is subjected to many different challenges, stressors, and opportunities. An important factor in handling these challenges is a positive self-concept and high self-esteem. Through adolescence, schools should be preparing students to become a comfortable part of the general population, easily adjusting to their surroundings. A population of students that requires closer attention are students who have been diagnosed with a learning disability. Students with learning disabilities are estimated to represent $2 \%$ to $10 \%$ of the student population. Students with learning disabilities struggle with self-concept and self-esteem, which in turn can lead to adjustment difficulties, substance abuse, depression, and suicide ideation.

According to Belmore and Cillessen, self-concept is the perception that individuals have of their own worth. This includes a composite of their feelings, a generalized view of their social acceptance, and their personal feelings about themselves. It develops as a result of one's experiences with the environment and ones evaluations of these experiences. Additionally, opinions of significant others, casual attributions and concrete feedback play a crucial role in the process of self-concept development [4]. The formative middle-school years of a child's life are an important time for the child to develop a positive self-concept. Self-concept is important because it contributes towards many different facets of a person's life, from childhood to adulthood.

A positive self-concept can lead to a fulfilling adulthood. Many different conditions can affect how students develop their self-concept. In a study by Marsh, it was found that a student's self-concept is partially dependent on his or her surroundings. He describes this as the big-fish-little-pond effect (BFLPE). Hughes and Baker indicate that children who have experienced rejection, humiliation, and failure generally have feelings of low self-worth and vulnerability [4]. Many children with LD experience these emotions more often than students without LD. This can have a profound effect on their academic selfconcept. The self-concept that is developed during this time carries over into adulthood.

Indian Journal of Mental Health 2015 
Because of this, it is important to consider the negative effects of LD, especially during adolescence [5].

State anxiety is an anxious response to a situation that the individual perceives as being threatening, such as a test or quiz. Meanwhile, trait anxiety is a persistent feeling of anxiety that does not depend on an anxiety-producing effect; people with this type of anxiety experience a low level, or hum, of anxiety throughout their day, which is considered a relatively stable personality characteristic. Trait anxiety has been characterized as "personality traits that can be conceptualized as relatively enduring differences among people in specifiable tendencies to perceive the world in a certain way and its dispositions to react or behave in a specified manner with predictable regularity" [7].

It has been stated that anxiety is "a series of responses indicative of a low expectancy of success in a valued-need area". In other words, anxiety is not produced unless the individual sees something as important. In addition, individuals with learning disabilities exhibit higher somatic complaints [8]. Research on learning disabilities and anxiety has found that anxiety affects both genders. For example, data on learning disabilities show that anxiety affects boys significantly more than it does girls, although it does affect girls negatively as well. However, most research in studies of both genders has focused on younger participants. Anxiety among individuals experiencing a learning disability has been shown to increase with age. A certain level of understandable anxiety exists among all adolescents as they transition from elementary school to middle and high schools, yet adolescents with learning disabilities seem to experience higher anxiety than adolescents without learning disabilities [7].

Learning disabilities can be extremely frustrating for children. Imagine having trouble with a skill all of your friends are tackling with ease, worrying about embarrassing yourself in front of the class, or struggling to express yourself. Things can be doubly frustrating for exceptionally bright children with learning disabilities-a scenario that's not uncommon. Kids with learning disabilities may have trouble expressing their feelings, calming themselves down, and reading nonverbal cues from others. This can lead to difficulty in the classroom and with their peers [9-10].

In a study conducted in Dharwad city, Karnataka, the relationship between self - esteem and adjustment among children with reading and writing difficulties was examined. It was found that children with reading and writing difficulties obtained significantly low score in self - esteem and adjustment when compared to normal children. Furthermore, children having reading and writing difficulty had poor scores on general and academic aspects of self-esteem and on peers and teachers related areas of adjustment. However, the differences between the groups were found to be low [11].

Chronic school failure is associated with poor academic and emotional functioning. School failure is a trademark of students with learning disabilities; consequently, children and adolescents with learning disabilities may be particularly vulnerable to emotional problems and school maladjustment. In their review of the literature, Bender and Wall suggested that children in heterogeneous learning disability samples are more susceptible to emotional and social problems than children with learning disability [12]. Previous studies have examined aspects of self - concept and adjustment in association to adolescents with learning disabilities, but there is limited research on these variables in relation to anxiety. The purpose of this study is to explore the relationship between anxiety and self - concept in adolescents with learning disabilities and anxiety and

Indian Journal of Mental Health 2015 
adjustment in adolescents with learning disabilities. The aim of the current study is to examine the impact of anxiety on the self - concept and the adjustment for adolescent students with learning disability.

\section{METHODOLOGY}

Once approval was obtained from the head of the department, consent forms were sent to the organization and to the parents of the all the students. Demographic details of each participant were collected at the time of testing. Only adolescent students, between the ages of 14-18 years were considered for this study. All questionnaires were assigned numerical codes to maintain confidentiality. The data on the questionnaires were coded and entered into an excel spreadsheet. To minimize error, the researcher verified all data coded and entered. The data was collected using the self - report survey from 110 students. All the students had been diagnosed with learning disability. Data was collected from various clinics and centres for learning disability and from special schools. Parental permission and permission from the organization was also obtained. Initially, the design of the current study was a $2 \times 2$ factorial design. Due to unavailability of data, a correlational design using cross - sectional data was used.

Demographic variables were measured using standard fact sheet items while other variables in the study were assessed using previously established selfreport instruments as well as measures developed for the overall study. The three scales which were used are -

\section{Revised Children's Anxiety and Depression Scale}

Revised Children's Anxiety and Depression Scale (RCADS) is a 47item, youth self-report questionnaire with subscales including: separation anxiety disorder $(S A D)$, social phobia (SP), generalized anxiety disorder (GAD), panic disorder (PD), obsessive compulsive disorder (OCD), and major depressive disorder (MDD). For the purpose of the current research, the scores on only the GAD subscale were calculated. This subscale consisted of 6 items [13].

\section{Self - Concept Questionnaire}

The Self - Concept Questionnaire provides six separate dimensions of self-concept, they are, Physical, Social, Intellectual, Moral, Educational and Temperamental Self-concept. It also gives a total self-concept score. The inventory contains 48 items. The summated score of all the forty-eight items provide the total self concept score of an individual. A high score on this inventory indicates a higher self-concept, while a low score shows low self-concept [14].

\section{Adjustment Inventory for School Students}

Adjustment Inventory for School Students (AISS), seeks to segregate well-adjusted secondary school students (age group 14 to 18 years) from poorly adjusted students in the 3 areas of adjustment: Emotional, Social and Educational. It consists of 60 items, 20 items in each area of adjustment [15].

Indian Journal of Mental Health 2015 


\section{Statistical Analysis}

Computerized statistical software was used to analyze data obtained from this study. To test the research questions, a correlation and regression analysis was performed to determine whether anxiety predict self - concept and whether anxiety predict adjustment.

\section{RESULTS}

Table 1 - Descriptive Statistics for Independent and Dependent Variables

\begin{tabular}{|lccccc|} 
& Minimum & Maximum & Mean & SD & Variance \\
\hline Anxiety & 30 & 98 & 50.25 & 16.206 & 262.65 \\
\hline Self - Concept & 103 & 220 & 159.05 & 24.628 & 606.558 \\
\hline Adjustment & 6 & 59 & 19.34 & 10.026 & 100.519 \\
\hline
\end{tabular}

Table 2 - Correlation between Adolescents' Anxiety and Self - Concept and Adolescents' Anxiety and Adjustment

\begin{tabular}{|cccc|}
\hline & Self - Concept & Adjustment \\
\hline Anxiety & Pearson Correlation & $-.377^{*}$ & $.219 *$ \\
\hline Sig. $(2-$ tailed $)$ & .000 & .021 \\
\hline $\mathrm{N}$ & 110 & 110 \\
\hline$* * \mathrm{p}<0.01, * \mathrm{p}<0.05$ &
\end{tabular}

Correlation coefficients were calculated for the following variables: anxiety \& self concept and anxiety \& adjustment. With reference to table 2, the correlations were significant at the 0.05 level. There was a significant negative correlation among anxiety and self - concept of -0.377 ( $p<0.01$ ). Anxiety and adjustment had a significant positive correlation of 0.219 ( $p<0.05$ ). Two simple linear regressions were performed to check whether anxiety is predictive of self - concept and if anxiety is predictive of adjustment. Results obtained as seen in table 3 indicate that, the $R$ value was -0.377 . The $R$ square value was 0.142 ( $p<0.01$ ) which indicated that $14.2 \%$ of the variance in self - concept can be explained by a change in anxiety. The adjusted $R$ square value is 0.134 i.e. $13.4 \%$ of the variance in self - concept can be explained by a change in anxiety. The findings thus indicate that there is a significant negative relationship between anxiety and the self conception an individual. However, the percentage of variance that can be explained by the predictor variable is extremely low. Results obtained as seen in table 5 indicate that the $R$ value was 0.219 . The $R$ square value was $0.048(p<0.05)$ which indicated that $4.8 \%$ of the variance in adjustment can be explained by a change in anxiety. The adjusted $\mathrm{R}$ square value is 0.039 i.e. $3.9 \%$ of the variance in adjustment can be explained by a change in anxiety. The findings thus indicate that there is a significant positive relationship between anxiety and the adjustment in an individual. However, the percentage of variance that can be explained by the predictor variable is extremely low.

Indian Journal of Mental Health 2015 
Table 3 - Model Summary of Simple Linear Regression between Adolescents' Anxiety and Self-Concept

\begin{tabular}{|c|c|c|c|c|c|c|c|c|c|}
\hline & & & \multicolumn{7}{|c|}{ Change Statistics } \\
\hline $\begin{array}{c}\text { Mode } \\
\text { I }\end{array}$ & $\mathrm{R}$ & $\mathrm{R}^{2}$ & $\begin{array}{c}\text { Adjuste } \\
\mathrm{d} \mathrm{R}^{2}\end{array}$ & $\begin{array}{l}\text { Std. } \\
\text { Error of } \\
\text { the } \\
\text { Estimat } \\
\text { e }\end{array}$ & $\begin{array}{c}\mathrm{R}^{2} \\
\text { Chang } \\
\mathrm{e}\end{array}$ & $\begin{array}{c}\mathrm{F} \\
\text { Change }\end{array}$ & df1 & $\mathrm{df} 2$ & $\begin{array}{c}\text { Sig. F } \\
\text { Change }\end{array}$ \\
\hline & -0.377 & 0.142 & 0.134 & 22.915 & 0.142 & 17.909 & 1 & 108 & 0.000 \\
\hline
\end{tabular}

Table 4 - Model Summary of Simple Linear Regression between Adolescents' Anxiety and Adjustment

\begin{tabular}{|c|c|c|c|c|c|c|c|c|c|}
\hline & & & & & \multicolumn{5}{|c|}{ Change Statistics } \\
\hline $\begin{array}{c}\text { Mode } \\
\text { I }\end{array}$ & $\mathrm{R}$ & $\mathrm{R}^{2}$ & $\begin{array}{c}\text { Adjuste } \\
\mathrm{d} \mathrm{R}^{2}\end{array}$ & $\begin{array}{l}\text { Std. } \\
\text { Error of } \\
\text { the } \\
\text { Estimat } \\
\text { e }\end{array}$ & $\begin{array}{c}\mathrm{R}^{2} \\
\text { Chang } \\
\mathrm{e}\end{array}$ & $\begin{array}{c}\mathrm{F} \\
\text { Change }\end{array}$ & df1 & $\mathrm{df} 2$ & $\begin{array}{c}\text { Sig. F } \\
\text { Change }\end{array}$ \\
\hline & 0.219 & 0.048 & 0.039 & 9.827 & 0.048 & 5.464 & 1 & 108 & 0.021 \\
\hline
\end{tabular}

\section{DISCUSSION}

The purpose of this research was to study the impact of anxiety on the self - concept and the adjustment for adolescent students with learning disability. The gender variable was not considered in the final analysis as enough data was not available about adolescent female students with learning disabilities. As a result, the study was modified and instead of studying the effect of anxiety and gender differences on the self concept and the adjustment, the impact of anxiety on self - concept and adjustment of adolescents with learning disabilities (LD) in Mumbai was studied. It was found that anxiety and self - concept had a negative correlation indicating that an increase in one would lead to a decrease in the other. Regression analysis revealed that the value of the coefficient of determination is 0.142 anxiety is predictive of self - concept.

The findings of the current research are consistent with past research that found that there is significantly higher anxiety and lower self-concept in the learning disabled children [8]. It was also consistent with another past research which found that students with LD reported higher levels of test anxiety and lower levels of self-esteem than their nondisabled peers and that, both students with LD and students with LD/ADHD reported significantly lower scores on academic self-concept, academic attributional style and academic self-efficacy beliefs than typically achieving peers [16-17]. The research also aimed at studying the relationship between anxiety and adjustment. It was found that anxiety and adjustment had a positive correlation indicating that an increase in one would 
lead to an increase in the other. Regression analysis revealed that the value of the coefficient of determination is 0.219 ; hence, anxiety is predictive of adjustment.

Though the results are significant, the findings seem counter - intuitive. There may be a number of factors why anxiety is positively correlated with adjustment. It could have happened that, they had anxiety but considering the fact they are all being given remedial education, therefore, this may have led to an improvement in adjustment. It could also be that most of these students have secure attachment with their parents which could be a protective factor. In most these centres, parents of these children were undergoing counseling so that they could deal with their kids better. A study highlighted the role of secure attachment as a protective factor in maintaining emotional adjustment among at-risk kindergartners with mild developmental delays. The findings showed the contribution of parents' positive and negative affect to children's adjustment, with differences for fathers' versus mothers' affect [18].

Qualitative analysis of the data revealed that 41 participants of the 110 participants had low anxiety, i.e., 32. $27 \%$ adolescent students with learning disabilities had low anxiety. Sixty - nine participants of the 110 participants had high anxiety, i.e., $62.72 \%$ adolescent students with learning disabilities had high anxiety. After interacting with some of the parents at the Clinics it was seen that the parents did not put any pressure on the child regarding academics or social activities. This paper will add to the understanding of the effects of anxiety on the self - concept and adjustment of adolescent students with learning disabilities, however, certain limitations to the study should be acknowledged. The data used for the analyses were collected through self-report questionnaires. Also, participants answered survey items based on their perception of their levels of anxiety, self - concept and adjustment. It is possible that parents or significant others may rate of their levels of anxiety, self - concept and adjustment differently.

Some institutions from where data was collected did not permit the researcher to interact with the student due to which rapport was not built. Lastly, the sample only consisted of participants with learning disability diagnosis; hence it was possible that the participants' primary learning disability diagnosis may have been comorbid with another undiagnosed disability that could have affected the findings of the study. While conducting the Adjustment Inventory for School Students, it was observed that most students couldn't understand the meaning of envy and debate, when asked, they said that now-a-days debated are not conducted in their schools. Future researchers may benefit from the findings and limitations of this study in order to better their research.

\section{REFERENCES}

1. Aro T, Jere-Folotiya J, Hengari J, Kariuki D, Mkandawire L. Learning and Learning Disabilities. In: Aro T, Ahonen T, editors. Assessment of learning disabilities: Cooperation between teachers, psychologists and parents. Finland: University of Turku; 2001. pp 11-26.

2. American Psychiatric Association. Diagnostic and statistical manual of mental disorders. 4th ed Text Revision. Washington DC: American Psychiatric Association; 2000.

3. John A, Sadasivan A, Sukumaran B, Bhola P, David NJ, Manickan LSS. Practice guidelines: Learning disability. Indian Journal of Clinical Psychology 2013;40(1):65-88.

4. Sternke JC. Self - concept and self - esteem in adolescents with learning disabilities [dissertation]. Menomonie (US): University of Wisconsin-Stout; 2010.

5. Elbaum B, Vaughn S. (2001). School-based interventions to enhance the self-concept of 
students with learning disabilities: A meta-analysis. The Elementary School Journal 2001;101 (3):303-29.

6. Sadock BJ, Sadock VA. Kaplan \& Sadock's synopsis of psychiatry. 10th ed. Philadelphia: Lippincott Williams \& Wilkins; 2007.

7. Custodero JL. Anxiety and Test Anxiety: General and Test Anxiety Among College Students with Learning [dissertation]. University of California; 2013.

8. Margalit M, Zak I. Anxiety and self-concept of learning disabled children. J Learning Disabil 1984;17(9):537-9.

9. Matsumoto D. The Cambridge dictionary of psychology. New York: Cambridge University Press; 2009.

10. Colman AM. Oxford dictionary of psychology. 3rd ed. New York: Oxford University Press Inc; 2009.

11. Patil M, Saraswathi G, Padakannaya P. Self-esteem and adjustment among children with reading and writing difficulties. Stud Home Comm Sci 2009;3(2):91-5.

12. Martínez RS, Semrud-Clikeman M. Emotional adjustment and school functioning of young adolescents with multiple versus single learning disabilities. J Learning Disabil 2004;37(5): 411-20.

13. Child First [Internet]. Los Angeles: University of California. Available from www.childfirst.ucla.edu

14. Saraswat RK. Self concept questionnaire. Agra: National Psychological Corporation; 1999.

15. Sinha AKP, Singh RP. Adjustment inventory for school students. Agra: National Psychological Corporation; 1993.

16. Peleg O. Test anxiety, academic achievement, and self-esteem among Arab adolescents with and without learning disabilities. Learning Disabil Quart 2009;32(1):11-20.

17. Tabassam W, Grainger J. Self-Concept, Attributional Style and Self-Efficacy Beliefs of Students with Learning Disabilities with and without Attention Deficit Hyperactivity Disorder. Learning Disabil Quart 2002;25(2):141-51.

18. Al-Yagon M, Mikulincer $M$. Socioemotional and academic adjustment among children with learning disorders: the meditational role of attachment-based factors. J Spec Educn 2004; 38(2):111-23.

Acknowledgement - Nil

Conflict of Interest - Nil

Funding - Nil

Indian Journal of Mental Health 2015 